\title{
On the pragmatics of logical connectives
}

\section{Are connectives truth-functional?}

\begin{abstract}
This paper discusses the issue of connectives in natural language, adopting a formalist approach in pragmatics. The outcome is that truth-conditional connectives are limited to conjunction, disjunction and conditional, and that negation, even in its metalinguistic and non-truth-conditional usages, has representational contextual effects, as suppressing a proposition and a presupposition or strengthening a proposition. As regards discourse connectives, they exhibits a strong pragmatic property, that is, they almost all exhibit factivity. Finally, quasi-synonym connectives, as causal ones, do not differ in meaning but in the way their conceptual and procedural meanings are distributed at different layers.
\end{abstract}

Keywords: conjunction, disjunction, conditional, negation, causal connectives, concessive connectives

\section{Introduction}

A small subset of connectives in natural language are clear counterparts of logical connectives. As we shall see, this is not tantamount to a question of identity of meaning rather than to a question of lexical entry, since the logical conjunction, disjunction, conditional as well as the operator of negation are linguistically translated in English as and, or, if and not.

Even if the relation between logical and linguistic meaning has given rise to a huge literature in semantics and pragmatics (e.g., Allwood, Andersson and Dahl 1977; Gazdar 1979; Mauri 2008; Humberstone 2011; Mauri and van der Auwera 2012), it is not completely clear whether linguistic uses of logical connectives should be connected to their logical meaning, that is, to truth-conditional meaning.

Jacques Moeschler, University of Geneva, Department of Linguistics, 1211 Genève 4, Switzerland, jacques.moeschler@unige.ch

Ә Open Access. (C) 2018 Jacques Moeschler, published by De Gruyter. (cc) BY-NC-ND This work is licensed under the Creative Commons Attribution-NonCommercial-NoDerivatives 4.0 License.

https://doi.org/10.1515/9783110607963-008 
In a nutshell, there are three principal positions about the relation between logical and linguistic meanings of logical connectives: a formalist account, represented by Gazdar (1979), a non-formalist one, represented by Ducrot (1989), and a Gricean perspective, mainly represented by neo-Gricean pragmatics (Horn 1972, 1984, 1989; Levinson 2000) and post-Gricean pragmatics (Blakemore 1987; Sperber and Wilson 1995; Carston 2002).

In this contribution, I will mainly advocate the formalist approach, even though this position seems to be the first to be abandoned due to the scarcity of its empirical covering. Though I have recently defended the Gricean perspective (Moeschler 2010, 2017a), I would like to formulate a very counterintuitive explanation. The main argument I will develop is that the formalist view is the only one which seems to give rise to some conclusions about semantic universals and general pragmatic principles. I will also point to some drawbacks of the neo- and post-Gricean explanations and will address a more general issue which is connected to the semantics-pragmatics interface (Moeschler forthc.).

In this paper, I will not deal with the non-formalist approaches, even though they address interesting questions from a pragmatic point of view (see Moeschler 2017a for a general comment on these approaches).

\section{The classic Gricean approach}

Let us start with the classic Gricean account of logical connectives. In the first pages of Logic and conversation, Grice (1975: 41, 43) addresses the issue of logical connectives as an introduction to his theory of meaning, claiming that the standard approaches in logic and philosophy of language - the formalist and the nonformalist ones - do not address accurately the relation between logical devices and natural languages:

It is a commonplace of philosophical logic that there are, or appear to be, divergences in meaning between, on the one hand, at least some of what I shall call the FORMAL devices $-\neg, \wedge, \vee, \supset,(\mathrm{x}), \exists(\mathrm{x}), \int \mathrm{x}$ (when these are given a standard two-valued interpretation) - and, on the other, what are taken to be their analogues or counterparts in natural language such expressions as not, and, or, if, all, some (or at least one), the. ... I wish, rather, to maintain that the common assumption of the contestants that the divergences do in fact exist is (broadly speaking) a common mistake, and that the mistake arises from an inadequate attention to the nature and importance of the conditions governing conversation.

In a nutshell, the Gricean story works like this: logical connectives have as semantics their logical truth-conditional meaning while their pragmatic uses are 
derived by implicature. For instance, the temporal meaning of the conjunction and is the result of the respect of the maxim of order ("be orderly"), the exclusive meaning of a disjunction (or) is the result of the respect of the first maxim of quantity ("make your contribution as informative as required (for the current purposes of the exchange)"), and the biconditional reading of if (conditional perfection) is a by-product of the second maxim of quantity ("do not make your contribution more informative than is required"), the maxim of relevance ("be relevant") and the submaxim of brevity ("be brief"). Examples (1) to (3) are illustrations of these uses.

(1) He took off his trousers and got into bed.

Implicature: 'He took off his trousers and then got into bed.'

(2) On a menu: Cheese or dessert.

Implicature: 'Not cheese and dessert.'

(3) If you mow the lawn, I owe you 10 euros.

Implicature: 'If you don't mow the lawn, I don't owe you 10 euros.'

Let us examine these three connectives.

\subsection{And-pragmatic meaning: implicature or explicature?}

The implicature type of solution meets with a lot of issues, however, the more serious having been addressed by Cohen (1971), Carston (2002) and Wilson and Sperber (2012) (see Blochowiak, Castelain and Moeschler 2015 for an experimental testing of this problem). First, as regards and-implicature, the Gricean explanation says nothing about when and is interpreted as 'and as a consequence'. In other words, the causal interpretation of and cannot be explained by any conversational maxim. So, in this case, (4) should be restricted to the meaning 'and then', and not 'and as a consequence':

(4) He turned the key and the engine started.

a. 'He turned the key and then the engine started.'

b. 'He turned the key and as a consequence the engine started.'

This has led Levinson (2000: 37, 114-115) to propose a different stance, in which the hearer is invited to enrich and-interpretation as far as he can, to obtain the 
most informative interpretation, via an I-implicature. In that case, the interpretation depends on the I-Principle and the I-heuristics:

\section{I-Heuristics}

What is expressed simply is stereotypically exemplified.

\section{I-Principle}

Speaker’s maxim: the maxim of Minimization; "Say as little as necessary”. ...

Recipient's corollary: The Enrichment Rule. Amplify the informational content of the speaker's utterance, by finding the most specific interpretation.

So, the I-heuristic invites the addressee to go up to the temporal, causal and consequence interpretation, the latter being the most informative one.

However, this explanation has given rise to some crucial issues, mainly because the non-truth-conditional pragmatic interpretation for and cannot explain why (5) is not a tautology. In effect, if $P$ and $Q$ and $Q$ and $P$ are truth-conditionally equivalent and $P$ and then $Q$ is an implicature, (5) should give rise, from a semantic point of view, to a non-informative reading and its logical structure (6) should be trivially true (from Wilson and Sperber 2012: 171).

(5) It's always the same thing at parties: either I get drunk and no-one will talk to me or no-one will take to me and I get drunk.

(6) P and Q, or $Q$ and $P$

Manifestly, in (5), $P$ and $Q$ does not equal truth-conditionally $Q$ and $P$, which has led Wilson and Sperber (2012) to propose that the and-enrichment is a process occurring not at the level of implicature but at the level of explicature, that is, the enriched and developed full propositional form. So, the only pragmatic reading of (5) is the result of a pragmatic process, occurring at the level of explicit content, as in (7).

\section{(7) $P$ and then $Q$, or $Q$ and then $P$}

In sum, the and case, which seems to be a paradigmatic case, combining both the logical meaning of a conjunction and the non-truth-conditional meaning of a generalized conversational implicature, does not bring any solution to the pragmatic enrichment issue.

The two other cases, or and if, illustrate similar problems, but with different consequences. 


\subsection{Or-meaning: why implicatures are not enough}

The second problematic case is illustrated by the or-implicature. In a Gricean framework, or triggers an implicature because the speaker has a choice for a stronger alternative, that is, and. So, if the speaker cannot assert $P$ and $Q$, he prefers to assert the strongest statement possible which does not flout the first maxim of Quality ("do not say what you believe to be false"). In other words, the use of or communicates the speaker's ignorance: he does not know which disjunct is true. This is clearly the case in the Gricean example in (8).

(8) Daughter: Where is mom?

Father: In the bathroom or the kitchen.

In this case, as the mother cannot be in both places at the same place, the only possible interpretation of or is its exclusive meaning, which is a stronger truthconditional meaning than the logical inclusive disjunction connective. Moreover, as regards its truth-conditional meaning, and is the strongest connective, since the conjunction is only true if both conjuncts are true.

Tab. 1: Truth conditions for conjunction $(\wedge)$, inclusive $(\vee)$ and exclusive disjunction $(\bar{v})$

\begin{tabular}{lllll}
\hline $\mathbf{P}$ & $\mathbf{Q}$ & $\mathbf{P} \wedge \mathbf{Q}$ & $\mathbf{P} \vee \mathbf{Q}$ & $\mathbf{P} \overline{\mathbf{V}}$ \\
\hline 1 & 1 & 1 & 1 & 0 \\
1 & 0 & 0 & 1 & 1 \\
0 & 1 & 0 & 1 & 1 \\
0 & 0 & 0 & 0 & 0 \\
\hline
\end{tabular}

However, the Gricean explanation does not make explicit the reason why the stronger connective for or is and and does not explain why the or-reading is not inclusive but exclusive. In other words, the explanation via the first Quantity maxim does not explain why this or-interpretation is more restricted and excludes the situation in which both disjuncts are true.

It is only in the neo-Gricean framework that this explanation is provided. More specifically, in Horn's (1972) proposal, the relevant notion is that of semantic scale: in a semantic scale $<\alpha$, $\beta$, where $\beta$ is a weaker expression than $\alpha$, that is, $\alpha$ entails $\beta$, the assertion of $\beta$ implicates the negation of $\alpha$. Gazdar (1979: 59) gives the following definition of a scalar (potential) implicature: 
$\Phi$ scalar-quantity-implicates that the speaker knows that it is not the case that $\Psi$ if and only if there is some sentence $\Psi$, just like $\Psi$, except that it contains a "weaker" scalar expression, and which is entailed by $\Phi$ and is either identical to $\Phi$ or form a part of it.

Now, how is it possible for or to implicate its exclusive meaning? Gazdar's (1979) reasoning uses a logical demonstration, based on or-implicature. Suppose that the semantic scale is $\langle a n d$, or $>$, as the truth conditions in Table 1 show. Then, the two following entailment $(\rightarrow)$ and implicature $(+>)$ relations hold, given in (9):

(9) Entailment: $P$ and $Q \rightarrow P$ or $Q$

Implicature: $\quad P$ or $Q+>$ not $(P$ and $Q)$

Gazdar's (1979: 59)'s simplified demonstration is given in (10).

(10) i. $P \vee Q$

ii. $\neg(P \wedge Q)$ implicature of (i)

iii. $P \bar{v} Q$ entailed by (i) and (iii)

Step (iii) must be explained: how can the exclusive meaning of a disjunction be entailed both by the inclusive disjunction and its implicature? Here is the explanation: the or-exclusive meaning is the conjunction of or-semantics and or-scalar implicature. This is made explicit in Table 2.

Tab. 2: Truth conditions for exclusive or

\begin{tabular}{lllllll}
\hline $\mathbf{P}$ & $\mathbf{Q}$ & $\mathbf{P} \vee \mathbf{Q}$ & $\mathbf{P} \wedge \mathbf{Q}$ & $\neg(\mathbf{P} \wedge \mathbf{Q})$ & $\mathbf{P} \vee \mathbf{Q}) \wedge \neg(\mathbf{P} \wedge \mathbf{Q})$ & $\mathbf{P} \bar{\vee} \mathbf{Q}$ \\
\hline 1 & 1 & 1 & 1 & 0 & 0 & 0 \\
1 & 0 & 1 & 0 & 1 & 1 & 1 \\
0 & 1 & 1 & 0 & 1 & 1 & 1 \\
0 & 0 & 0 & 0 & 1 & 0 & 0 \\
\hline
\end{tabular}

What is surprising is that the implicature is not enough, since the meaning of $\neg(P$ $\wedge Q)$ makes the implicature true when both disjuncts are false. Let us comment on this problem.

Suppose that we must choose between two menus in a French restaurant. Menu 1 costs $30 €$ and includes fromage et dessert 'cheese and dessert'. Menu 2 costs only $25 €$ and mentions fromage ou dessert 'cheese or dessert'. So, the choice 
is simple. If you want both, you choose menu 1 and, if you want only one plate after the main course, you choose menu 2. Now you know two things by choosing menu 2: first, you cannot have both - this is the not ( $P$ and $Q$ ) implicature meaning - and, second, you can choose one item between cheese and dessert. Suppose now that you want a dessert after having chosen cheese in menu 2. The waiter will politely recall that fromage ou dessert does not mean both. If you agree and nevertheless want some dessert, then you should pay extra money for it. This seems perfectly reasonable, from a logical and pragmatic point of view. Now suppose that you want cheese and the waiter is embarrassed because there is no more cheese, only dessert. You can accept this but one constraint is not satisfied: even if the client cannot have both, he can choose one of the two and the restaurant must provide both. Finally, suppose that, after the waiter's negative answer about cheese, he answers again negatively in case you accept a dessert. In that case, you are right in having the impression that a maxim has been flouted. Nevertheless, exactly as in the second case, the strict truth-conditional interpretation makes this situation true of or-scalar implicature!

Here is the main issue: what is implicated cannot encompass speaker meaning, since what the restaurateur wants to say (means) by writing on the menu fromage ou dessert is that only one item can be chosen, even though he is committed to having both. In any case, the pragmatic meaning of fromage ou dessert cannot be compatible with neither cheese nor dessert. But this is what the truth conditions of not (cheese and dessert) predict.

The solution, as shown in Table 2, comes from conjoining the or-inclusive meaning with its implicature. In this case, the situation predicted when both propositions are false is ruled out. So, the correct and exclusive meaning, that is, the or-exclusive meaning, is obtained via the or-inclusive meaning conjoined with its implicature.

Now, if we recall Grice's definition of conveyed meaning, we encounter the classic definition proposed by neo-Griceans (Horn 2004) of what is communicated: what is communicated is the addition of what is said and what is implicated. What is said here is the or-inclusion meaning, what is implicated is the negation of the strong alternative expression in the scale, that is, and.

In sum, the or-case shows that the meaning of an implicature does not exhaust speaker meaning, which raises the question why we must compute implicatures. The answer is that by doing so, we access speaker's meaning indirectly (see Moeschler 2017b, 2017c for a complete proposal about scalar implicature of quantifiers and speaker meaning). 


\subsection{If and the issue of counterfactuals}

The third issue is linked to conditional if. Since Geis and Zwicky's (1971) influential paper On invited inferences, the pragmatic analysis of conditionals has converged on the biconditional interpretation of ordinary conditionals (see also de Cornulier 1985 for an extensive analysis of French si; van der Auwera 1997a, 1997b for a general discussion of conditional "perfection"). In other words, ordinary conditionals lead to the biconditional analysis, whose truth conditions are given in Table 3 and logical property in (11).

Tab. 3: Truth conditions for conditional $(\rightarrow)$ and biconditional $(\leftrightarrow)$

\begin{tabular}{llll}
\hline $\mathbf{P}$ & $\mathbf{Q}$ & $\mathbf{P} \rightarrow \mathbf{Q}$ & $\mathbf{P} \leftrightarrow \mathbf{Q}$ \\
\hline 1 & 1 & 1 & 1 \\
1 & 0 & 0 & 0 \\
0 & 1 & 1 & 0 \\
0 & 0 & 1 & 1 \\
\hline
\end{tabular}

(11) if and only if $P$, then $Q$ is equivalent to if $P$ then $Q$ and if $Q$ then $P$

$$
P \leftrightarrow Q={ }_{d f}(P \rightarrow Q) \wedge(Q \rightarrow P)
$$

The pragmatic explanation goes as follows: the use of a conditional in natural language implicates its biconditional meaning. In other words, what is excluded in the biconditional meaning is the situation where the antecedent is false and the consequent is true. This means that a conditional can be true in only two cases: first, when both antecedent and consequent are true and, second, when both are false. These two situations are, from a pragmatic point of view, quite plausible: when both the antecedent and the consequent are true, it makes sense that the conditional relation is true. Conversely, if there is a conditional link, this link is still the case when both propositions are false. These two cases are respectively represented by the suppositional use of conditionals, often called "ordinary conditional" (Moeschler and Reboul 2001) and the "counterfactual" use (Lewis 1973).

So, from a strict truth-conditional perspective, both the ordinary and the counterfactual uses make sense of the truth conditions of the biconditional. Let us examine first the ordinary use in (12). 
(12) If Peter comes to the party, Mary will be happy.

If both the antecedent and the consequent are true in (12), then, if the antecedent is true, the consequent must be true. There are two possible explanations for this fact. The first one is the result of an invited inference: by asserting if $P, Q$, the speaker means or conversationally implicates if not- $P$, not- $Q$. Thus, the biconditional meaning is, from a strict logical point of view, what the speaker conveys or communicates: what is said (if $P, Q$ ) plus what is implicated (if not- $P$, not- $Q$ ) equals what is communicated (if and only if $P, Q$ ).

Of course, the implicature type of explanation should accommodate the cancellation of the implicature. This seems to be correct, since (13) is not contradictory. In other words, the biconditional implicature can be cancelled without contradiction.

(13) If Peter comes to the party, Mary will be happy but, if he does not come, Mary will be happy anyway.

The second explanation is more pragmatic but it only covers a small part of conditional uses, that is, conditionals implying a causal relation. In effect, some ordinary conditionals do not imply any causal relation between the antecedent and the consequent, as in (14).

(14) If this is a triangle, then the sum of its angles equals $180^{\circ}$.

In (14), the relation between the two propositions is that of a definition: the sum of the angles of a triangle is equal to $180^{\circ}$ (see Blochowiak 2017 for more on definitions in relation to connectives).

In contrast, in (12), the relation is causal: Peter's presence at the party will cause Mary's happiness. This causal relation is between events and, more specifically, future events. The temporal operator FUTURE, in this case, scopes over each proposition and not over the conditional relation. So, (15) is the correct semantic interpretation but (16) is not. (16) is best translated as in (17) whereas, in French, the consequent is most frequently in the simple future, as in (18).

(15) if FUTURE (Peter comes), then FUTURE (Mary is happy)

(16) FUTURE (if Peter comes, then Mary is happy) 
(17) In the future, if Peter comes, Mary will be happy.

(18) Si Pierre vient à la réception, Marie sera heureuse.

'If Peter comes to the party, Mary will be happy.'

The causal interpretation is not restricted to ordinary conditionals. In the counterfactual one, as in (19), the causal relation is still the case but it concerns past counterfactuals events.

(19) Si Pierre était venu, Marie aurait été heureuse.

'If Peter had come, Mary would have been happy.'

What about a causal past relation with no counterfactual interpretation? Apparently, the conditional connective cannot express such a relation. This does not mean that such relations cannot be expressed. A typical causal connective is because (French parce que). So, the content causal interpretation of parce que may be a past content causal relation (Sweetser 1990), as in (20), as well as a present one as in (21), but not a future one as in (22), whose only possible reading is that of a speech act (Sweetser 1990), as in (23).

(20) Marie était contente parce que Pierre est venu.

'Mary was happy because Peter came.'

(21) Marie est contente parce que Pierre est là.

'Mary is happy because Peter is there.'

(22) \# Marie sera contente parce que Pierre sera là.

'Mary will be happy because Peter will be there.'

(23) (J'affirme que) Marie sera contente, parce que Pierre sera là.

'(I affirme that) Mary will be happy because Peter will be there.'

So, ordinary conditionals express future causal relations, while causal connectives are devoted to past and present causal ones. What is more striking is the systematic use of irrealis tenses (like the French conditional and the English subjunctive) for expressing counterfactual conditionals. French imparfait describes a counterfactual state or event in the present whereas the French plus-que-parfait 
describes a past counterfactual state or event (Moeschler and Reboul 2001). The same holds, respectively, for the consequent clause, with the present conditional and the past conditional, as (24) to (27) show.

(24) Si Marie était heureuse, elle nous le dirait.

'If Mary were happy, she would tell us.'

(25) Si Marie avait été heureuse, elle nous l'aurait dit.

'If Marie had been happy, she would have told us.'

(26) Si Pierre venait, Marie partirait avec lui.

'If Peter came, Mary would leave with him.'

(27) Si Pierre était venue, Marie serait partie avec lui.

'If Peter had come, Mary would have left with him.'

\subsection{Conclusion}

In sum, conditionals in natural language seem to be much more complex than involving simply a logical conditional relation (material implication) or the biconditional interpretation (equivalence relation). Moreover, the classic Gricean story seems to be rather poor as an explanation of the pragmatic enrichment of conditionals.

The temptation is thus to abandon the logical description of logical connectives in natural language and to look for more basic cognitively motivated concepts for describing the uses of logical connectives. For instance, concepts like temporal succession and causality for and, doubt for or and supposition for if could be invoked. Although this path is often followed in cognitive and functional linguistics, I would like to propose a formalist explanation and come back to a very strong argument given by Gazdar (1979) for explaining truth-functional connectives in natural language. I will argue that his explanation can give some answers to the question of relations between logical connectives and semantic universals (von Fintel and Matthewson 2008). 


\section{The formalist approach}

To my knowledge, Gazdar's (1979) approach has not been developed in pragmatics (for an exception, see Moeschler and Reboul 1994: Ch. 6). However, he proposes a very convincing argument restricting truth-functional connectives (TFCs) to and and or.

\subsection{TFC}

There are sixteen possible TFCs, because the two arguments (propositions) are combined with four truth values: 1-1, 1-0, 0-1, 0-0. They are provided in Table 4 (Gazdar 1979: 69; see Lohiniva 2014 for a full discussion) - the alphabetic labels are Gazdar's (1979).

Tab. 4: Sixteen possible TFCs

\begin{tabular}{llllllllllllllllll}
\hline $\mathbf{P}$ & $\mathbf{Q}$ & $\mathbf{A}$ & $\mathbf{B}$ & $\mathbf{C}$ & $\mathbf{D}$ & $\mathbf{E}$ & $\mathbf{F}$ & $\mathbf{G}$ & $\mathbf{H}$ & $\mathbf{I}$ & $\mathbf{J}$ & $\mathbf{K}$ & $\mathbf{L}$ & $\mathbf{M}$ & $\mathbf{0}$ & $\mathbf{V}$ & $\mathbf{X}$ \\
\hline 1 & 1 & 1 & 1 & 1 & 0 & 1 & 0 & 0 & 1 & 1 & 0 & 1 & 0 & 0 & 0 & 1 & 0 \\
1 & 0 & 1 & 1 & 0 & 1 & 0 & 0 & 1 & 0 & 1 & 1 & 0 & 1 & 0 & 0 & 1 & 0 \\
0 & 1 & 1 & 0 & 1 & 1 & 0 & 1 & 0 & 1 & 0 & 1 & 0 & 0 & 1 & 0 & 1 & 0 \\
0 & 0 & 0 & 1 & 1 & 1 & 1 & 1 & 1 & 0 & 0 & 0 & 0 & 0 & 0 & 0 & 1 & 1 \\
\hline
\end{tabular}

A corresponds to $\checkmark$ (inclusive disjunction), B to $\leftarrow$ (material implication from Q to $\mathrm{P}$ ), $\mathrm{C}$ to $\rightarrow$ (material implication), $\mathrm{D}$ to $\uparrow(\neg \wedge), \mathrm{E}$ to $\leftrightarrow$ (biconditional), $\mathrm{F}$ to $P, \mathrm{G}$ to $\neg Q, \mathrm{H}$ to $Q, \mathrm{I}$ to $P$, J to $\bar{V}$ (exclusive disjunction), $\mathrm{K}$ to $\wedge$ (conjunction), $\mathrm{L}$ to $\nrightarrow$ $(\neg \rightarrow)$, M to $\nleftarrow(\neg \leftarrow)$, $\mathrm{O}$ to $\perp$ (contradiction), $\mathrm{V}$ to $T$ (tautology) and $\mathrm{X}$ to $\downarrow(\neg \vee)$.

To make this system easier, Gazdar (1979) proposes to reduce the number of connectives to eight, by grouping the arguments to three sets of truth values: $\{1\}$ $=1-1,\{0,1\}=1-0$ and $0-1,\{0\}=0-0$. Table 5 shows the new set of TFCs, that is, the relevant set for deciding which connective is a TFC.

Tab. 5: Candidates for TFCs in natural language

\begin{tabular}{lllllllll}
\hline Arguments & $\mathbf{A}^{*}$ & $\mathbf{D}^{*}$ & $\mathrm{E}^{*}$ & $\mathbf{J}^{*}$ & $\mathbf{K}^{*}$ & $\mathbf{O}^{*}$ & $\mathbf{V}^{*}$ & $\mathbf{X}^{*}$ \\
\hline$\{1\}$ & 1 & 0 & 1 & 0 & 1 & 0 & 1 & 0 \\
\hline
\end{tabular}




\begin{tabular}{lllllllll}
\hline Arguments & $\mathbf{A}^{*}$ & $\mathbf{D}^{*}$ & $\mathrm{E}^{*}$ & $\mathbf{J}^{*}$ & $\mathbf{K}^{*}$ & $\mathbf{O}^{*}$ & $\mathbf{V}^{*}$ & $\mathbf{X}^{*}$ \\
\hline$\{0,1\}$ & 1 & 1 & 0 & 1 & 0 & 0 & 1 & 0 \\
$\{0\}$ & 0 & 1 & 1 & 0 & 0 & 0 & 1 & 1 \\
\hline
\end{tabular}

Now, we must decide which connective is a TFC. $\mathrm{O}^{\star}$ (contradiction) is not relevant for natural language: it would mean that sentences in (28) receive the same truth value, that is, the value "false", whether the sentences are true or false. It can thus be abandoned.

(28) a. Geneva is an international city (1) $0^{\star}(0)$ Bern is the capital of Switzerland (1).

b. Geneva is not an international city (0) $\mathrm{O}^{\star}(0)$ Bern is the capital of Switzerland (1).

c. Geneva is not an international city (0) $\mathrm{O}^{\star}(0)$ Bern is not the capital of Switzerland (0).

The same argument can be used for $\mathrm{V}^{\star}$ (tautology), because it would result in considering all sentences in (28) to be true.

The criterion used by Gazdar (1979) is the principle of confessionality. This principle states that a TFC cannot yield a true proposition from false arguments. In other words, a TFC (C) must confess the falsity of its argument, by giving thus a false truth value to false arguments:

(29) A connective $c \in C$ is confessional iff $c(\{0\})=0$

(Gazdar 1979: 76)

This criterion, which refers to the first maxim of Quality ("do not say what you believe to be false”), allows us to reject connectives $\mathrm{D}^{\star}, \mathrm{E}^{\star}$ and $\mathrm{X}^{\star}$, all yielding a truth value true 1 with false arguments $0 . \mathrm{O}^{\star}$ and $\mathrm{V}^{\star}$ have been put aside for reason of relevance, as discussed before. $\mathrm{D}^{\star}$ is not a classical connective in logic $(\uparrow$ or $\neg \wedge$ ), but $E^{\star}$ corresponds to the equivalence or biconditional connective $(\leftrightarrow$, if and only if). So, the last candidates are $\mathrm{A}^{\star}, \mathrm{J}^{\star}$ and $\mathrm{K}^{\star}$. $\mathrm{A}^{\star}$ corresponds to inclusive or (inclusive disjunction), $\mathrm{J}^{\star}$ to exclusive or (exclusive disjunction) and $\mathrm{K}^{\star}$ to and (conjunction). As we demonstrated that exclusive or can be derived from inclusive or, the only possible TFCs in natural language are inclusive disjunction and conjunction, that is, or and and. These two connectives are predicted to be semantic universals. 
So far so good, but what about negation and conditional? I would like to argue that negation satisfies the same test as disjunction and conjunction and that conditional, being a non-confessional connective, must be explained at another level, that is, reasoning. Finally, if the principle of confessionality is the right pragmatic criterion, then it must follow that all connectives in natural language must be confessional. I will show in Section 5 that this is the case, at least for causal and concessive connectives.

\subsection{Negation}

Negation is a unary operator, because it has only one argument. There are four possible unary operators, because the truth values for the argument are combined $\left(2^{2}\right)$. They are provided in Table 6 (Gazdar 1979: 68).

Tab. 6: Possible unary operators in natural language

\begin{tabular}{lllll}
\hline Argument & $\mathbf{T}$ & $\mathbf{N}$ & $\mathbf{P}$ & $\mathbf{Q}$ \\
\hline 1 & 1 & 0 & 1 & 0 \\
0 & 0 & 1 & 1 & 0 \\
\hline
\end{tabular}

So, what has to be explained is why natural language only have $N$ as an operator, that is, negation.

First, $\mathrm{T}$ is eliminated by the submaxim of Manner ("be brief"): there is an equivalence between any proposition $\phi$ and $T \phi$ : $T \phi \leftrightarrow \phi$.

Second, $\mathrm{P}$ and $\mathrm{Q}$ are eliminated because of the maxim of Relation ("be relevant"): whatever the truth value of $\phi$ and $\psi, P \phi$ is true and $P \psi$ is true, which yields the equivalence between $P \phi$ and $P \psi: P \phi \leftrightarrow P \psi$. The same reasoning holds for the operator $\mathrm{Q}$, but with a false truth value: $Q \phi$ is always false and $Q \psi$ is always false, so $Q \phi \leftrightarrow Q \psi$. Thus, only $\mathrm{N}$ is available for natural languages. Moreover, $\mathrm{N}$ can be used to define T: $T \phi \leftrightarrow N N \phi$.

In sum, negation is the only unary possible operator for natural language. This is good news, because it implies that a negative statement is the falsehood of the proposition over which the negation scopes. 


\subsection{Conditionals and reasoning}

The last issue regards conditionals, because material implication and the equivalence connective are not confessional TFCs - they yield a true proposition from false arguments.

One argument against the principle of confessionality for maintaining conditional and equivalence connectives as TFCs is reasoning. In what follows, I will give a similar argument to Gazdar's (1979) for disjunction: as the more specific connective can be obtained via implicature, only the broader one should be considered as a TFC, that is, either the unilateral conditional or material implication $(\rightarrow$ or $\supset)$.

Contrary to other connectives, like conjunction, which gives rise to analytic deductive elimination rules $(P \wedge Q \vdash P, P \wedge Q \vdash Q$ ), deductive elimination rules for conditional are synthetic rules (Sperber and Wilson 1995): they yield a true conclusion from two premises, and not from one premise as with analytical rules ( $\wedge$-elimination rule).

There are two deductive elimination rules for the conditional connective: $m o-$ dus ponens and modus tollens, given in (30) and (31) respectively.

(30) Modus ponens

inputs (i) $P \rightarrow Q$

(ii) $P$

output $\quad Q$

(31) Modus tollens

inputs (i) $\quad P \rightarrow Q$

(ii) $\neg Q$

output

$\neg P$

These deductive rules contrast with the deductive schema of an invited inference, which leads to a logically false conclusion (see Mercier and Sperber 2017: 26 for an explicit discussion of conditional inferences), as in (32).

(32) Invited inference

inputs (i) $\quad P \rightarrow Q$

(ii) $\quad \neg P$

output $\quad \neg Q$ 
Imagine the following situation: Paul and Susan are concerned about Mary, because Peter might be present or absent. Susan says if Peter comes, Mary will be happy. Two scenarios could happen. First, Peter comes and then Paul and Susan are relieved: Mary will be happy, unless Susan has said something false. So, Susan and Paul's reasoning assumes a true premise, yielding a true conclusion. In other words, what makes sense then of a conditional is that it is presumed to be true. Of course, the bet is the truth of the antecedent.

What happens if the antecedent is false? In that case, the conclusion is pragmatically inferred as false. In our scenario, if Susan hears that Peter cannot come (he missed his plane), then she concludes that Mary will not be happy. However, there is absolutely no logical grounding for this conclusion. The conditional could be true in case the antecedent is false and the consequent true, as Table 3 shows.

Now, what about the counterfactual interpretation? Susan says if Peter had been there, Mary would have been happy. Here, neither the antecedent nor the consequent are true: the counterfactual interpretation is obtained because both propositions are supposed to be false. In that case, two ways of obtaining the counterfactual interpretation are possible. The first path is to use the invited inference schema: in that case, the falsehood of the antecedent implicates the falsehood of the consequent. The second path is using the modus tollens schema. Suppose Mary appears to be unhappy: in that context, the conditional plus the negation of the consequent leads to the negation of the antecedent, that is, Peter did not come. In other words, the counterfactual interpretation is obtained either by forward (invited inference) or backward (modus tollens) reasoning.

So, if the inference schemas are incorporated in the semantics of if, then if can be a TFC even though it is not a confessional connective.

\subsection{Conclusion}

In conclusion, we have good reasons to define the set of TFCs as including conjunction, disjunction, conditional and negation. As they are defined truth-conditionally, this means that their semantics are minimal and can be captured by their logical meanings. All the possible pragmatic readings (temporal for and, exclusive for or, biconditional for if) are obtained by pragmatic inference.

To have a complete picture, we should explain some uses of negation classified as metalinguistic, because they are a priori non-truth-conditional. 


\section{Metalinguistic negation}

\subsection{The classic approaches}

Metalinguistic negation is a use of negation where the speaker does not want to deny a positive utterance, as in descriptive negation, but refuses to assert a previous assertion (Horn 1985, 1989), as in (33) to (41).

(33) Around here we don't eat tom[eiDouz] and we don't get stressed out. We eat tom[a:touz] and we get a little tense now and then.

(34) Mozart's sonatas weren't for violin and piano, they were for piano and violin.

(35) I didn't manage to trap two mongeese: I managed to trap two mongooses.

(36) Anne doesn't have three children, she has four.

(37) You didn't eat some of the cookies, you ate all of them.

(38) It isn't possible she'll win, it's downright certain she will.

(39) John isn't patriotic or quixotic, he's both patriotic and quixotic.

(40) I'm not happy - I'm ecstatic.

(41) It's not warm out; is downright hot.

In all these examples, there is no denial of a proposition but the speaker's refusal of asserting a proposition. In Horn's $(1985,1989)$ analysis, negation is unambiguously truth-conditional but the use of negation in (33) to (41) is not truth-conditional: the speaker refuses to assert the proposition under the scope of negation.

Let us take as a paradigmatic example (36) - for examples such as (33) to (35), see Moeschler (1997). Let us analyse (36) as follows (Moeschler 2013a): 
(42) Anne doesn't have three children (NEG), she has four (COR).

a. $C O R \rightarrow P O S$

b. not (Anne has exactly three children)

First, the corrective clause (COR) entails the positive counterpart of the negative clause (POS): in effect, if X has four children, then X has three children. Second, what does negation scope over? It cannot be POS, because this would imply that POS is under the scope of negation and simultaneously entailed by COR, which would lead to a contradiction, as shown in (43).

(43) not (Anne has three children) and (Anne has three children)

So, in (42), negation does not scope over the positive counterpart (POS) but over the implicature of POS (i.e., 'Anne has no more than three children'). In that case, (42) is no longer contradictory, as (44) shows.

(44) not (Anne has exactly three children) and (Anne has four children)

Now we know why utterances of the form NEG, COR with metalinguistic negation are not contradictory. However, there is a surprising consequence of this analysis.

\subsection{The representational approach}

In some recent papers (Moeschler 2013a, 2017c), I demonstrated that metalinguistic negation, when it scopes over an implicature, has representational effects. In Moeschler (2010) and (2013a), I use the same types of arguments to describe propositional effects resulting from presuppositional negation, when negation scopes over the assertion and the presupposition:

(45) Abi does not regret to have failed (NEG), because she passed (COR).

In (45), she passed (COR) defeats both the assertion Abi regrets that $P$ (POS) and its presupposition Abi failed.

In both cases, metalinguistic negation scoping over an implicature and a presupposition, the contextual effects are representational: 
(46) Contextual effect of metalinguistic negation scoping over a scalar implicature:

strengthening of POS

(47) Contextual effect of presuppositional negation:

suppression of POS and POS presupposition

In other words, both uses of metalinguistic negation entail and implicate representational effects. If this is true, then metalinguistic negation not- $P$ means 'the speaker cannot affirm that $P$ ' and has representational effects. As a conclusion, metalinguistic uses are not special cases of non-truth-conditional meaning: on the contrary, they support a truth-conditional analysis.

\section{Discourse connectives as TFCs}

One of the main questions that pragmatics must answer is why natural languages display a great number of discourse connectives, such as causal, temporal and concessive ones. At a first glance, none of these connectives seems to exhibit a truth-conditional meaning. Even though a truth-conditional meaning could be partially relevant at the semantic level, the meanings of discourse connectives seem to focus on other properties.

Let us take the but example. But has truth-conditional properties, like the conjunction and. One test for this type of meaning is the equivalence of truthconditional meanings between $P$ but $Q$ and $Q$ but $P$ :

(48) a. Paul is smart but lazy.

b. Paul is lazy but smart.

(48a) has the same truth conditions as (48b) but certainly not the same pragmatic meaning. (48a) is negatively oriented and leads to the conclusion that Paul's laziness is a stronger argument than his smartness (Anscombre and Ducrot $1977,1983)$. On the other hand, (48b) is positively oriented: the sequences in (49) and (50) show that different conclusions are obtained (cf. Ducrot 1980 for the concept of argumentative orientation).

(49) a. Paul is smart, but lazy: he is not the right person for the TA position.

b. \# Paul is smart, but lazy: he is the right person for the TA position. 
(50) a. Paul is lazy, but smart: he is the right person for the TA position.

b. \# Paul is lazy, but smart: he is not the right person for the TA position.

As a second property, both conjuncts with but must be true: all the combinations in (51) show that Paul is smart and Paul is lazy must be true if they appear in the sequence $X$ but $Y$.

(51) a. \# Paul is smart but not lazy.

b. \# Paul is not smart but lazy.

c. \# Paul is not smart but not lazy.

Which conclusions can we draw from these facts? Are they specific to but or do they, on the contrary, illustrate a general property of discourse connectives? I would like to make the following stipulation: all discourse connectives exhibit factivity, only a few of them being non-factive.

Let us first discuss one possible counterexample. In French, puisque 'since' exhibits some interesting properties (Groupe $\lambda$-1 1975; Zufferey 2010, 2012).

First, puisque can have a counterfactual use (Groupe $\lambda$-1 1975). In (52), the speaker knows that his addressee does not know everything and is therefore unable to give him the first three finishers.

(52) Puisque tu sais tout, donne-moi le tiercé.

'Since you know everything, give me the first three finishers (in horse race).'

Second, and more generally, puisque introduces old or presupposed information, belonging to the common ground, as (53) shows.

(53) Puisque tu es là, allons dans le salon.

'Since you are here, let us go to the living room.'

Other causal connectives, like parce que 'because', are factive: parce que cannot be used if the cause and the consequence are false (Blochowiak 2010, 2014; Moeschler 2016). Even when the causal relation is under the scope of negation, as in (54), negation does not scope over any propositions (presupposed as true) but over the causal relation, as in (55). 
(54) Paul n'est pas tombé parce que Marie l'a poussé, mais parce qu'il s'est pris les pieds dans une racine.

'Paul did not fall because Mary pushed him but because he walked on a root.'

(55) not (Mary pushed John CAUSE John fell) and (John walked on a root CAUSE John fell)

Concessive connectives, on the other hand, defeat one specific inference, like mais 'but', pourtant 'however' and bien que 'although' (Lakoff 1971; Anscombre and Ducrot 1977; Moeschler 1989; Lohiniva 2017). For instance, the same concessive relation can be expressed by different connectives in French, as (56) to (58) show.

(56) Il est républicain mais honnête.

'He is a Republican but honest.'

(57) Il est républicain, pourtant il est honnête.

'He is a Republican; he is honest, however.'

(58) Bien qu’il soit républicain, il est honnête.

'Although he is a Republican, he is honest.'

In each example, a false inference contrasts with the second conjunct: the expected inference is he is not honest. This is clearly an unexpected statement in the case of bien que: in bien que $P, Q, Q$ is less likely to be the case than not- $P$ (Lohiniva 2017) - see the use of the French subjunctive with bien que. On the other hand, in the case of mais, the inference is forward ( $X$ is republican $+>X$ is not honest) whereas, in the case of pourtant, the reading is either forward or backward ( $X$ is honest $+>X$ is not a Republican). In each situation, both conjuncts are asserted as true, as the negation test in (59) and (60) shows for pourtant and bien que.

(59) a. \# He is not a Republican, pourtant he is honest.

b. \# He is a Republican, pourtant he is not honest.

c. \# He is not a Republican, pourtant he is not honest. 
(60) a. \# Bien que he is not a Republican, he is honest.

b. \# Bien que he is a Republican, he is not honest.

c. \# Bien que he is not a Republican, he is not honest.

So, what is the difference in meaning between these quasi-synonymous connectives in French? Contrary to logical connectives, where the pragmatic meaning is the result of a narrowing of their logical meaning (enrichment), the semantic meaning of concessive cannot be extended from the logical conjunction meaning.

In Moeschler (2016), I proposed a general answer to this puzzle, which is crucial for explaining why connectives are so pervasive in natural language.

First, some connectives show a general conceptual relation, or a relational concept, which can be captured by concepts like CAUSE or CONTRAST. These concepts are assumed to be part of the conceptual meaning of connectives. These meanings are not truth-conditional because they cannot be expressed by one of the sixteen TFCs. Conceptual meaning includes not only a conceptual relation, like cause, but also all its possible entailments. For instance, in its causal uses, donc 'therefore' does not entail the consequence $Q$ in $P$ donc $Q$, because the speaker is responsible for the inference. Hence, donc is not a factive connective. A test for demonstrating the non-factivity of donc is the possible adjunction of an epistemic modal predicate in the consequence clause, as in (61).

(61) a. Marie a poussé Jean, donc il est tombé.

'Mary pushed John donc he fell.'

b. Marie a poussé Jean, donc il a dû tomber.

'Mary pushed John donc he must have fallen.'

Second, beside its conceptual meaning, a connective has a procedural meaning, which is about, as regards causal connectives, the direction of the causal relation. What is striking is that French parce que is the only backward connective (Moeschler 2011), as in (62). In effect, when donc is backward, its use is not causal, but inferential: in $P$ donc $Q$, the speaker's inference is about a possible cause $Q$, as in (63).

(62) Jean est tombé parce que Marie l'a poussé.

'John fell because Mary pushed him.' 
(63) Jean est tombé, donc Marie l'a poussé.

'John fell, donc Mary pushed him.'

Finally, conceptual meaning can intervene at the level of explicature (parce que) or implicature (et, donc), this distinction being based on the cancellation test implicatures are cancellable, explicatures are not. Table 7 gives a summary of such an analysis (Moeschler 2016: 134).

Tab. 7: A chart for causal connectives

\begin{tabular}{|c|c|c|c|c|}
\hline \multirow{2}{*}{$\begin{array}{l}\text { Meaning } \\
\text { Connectives }\end{array}$} & \multicolumn{3}{|l|}{ Conceptual } & \multirow{2}{*}{$\begin{array}{l}\text { Procedural } \\
\text { Direction of CAUSE }\end{array}$} \\
\hline & Entailment & Explicature & Implicature & \\
\hline parce que & Q & CAUSE $(X, Y)$ & & $\mathrm{Q} \rightarrow \mathrm{P}$ \\
\hline donc & $P$ & & POSSIBLE_CAUSE $(X, Y)$ & $P \rightarrow Q$ \\
\hline et & Q & & POSSIBLE_CAUSE $(X, Y)$ & $P \rightarrow Q$ \\
\hline
\end{tabular}

In sum, what makes discourse connectives specific in natural languages is not their non-truth-functionality but their conceptual and procedural meanings. The proposal made in Moeschler (2016) assumes that the slight meaning differences between quasi-synonymous connectives do not lie in the difference of conceptual or procedural meanings but in the way conceptual and procedural meanings are distributed within different layers of meanings. Broadly speaking, the meaning bricks of connectives are dispatched at different layers of meaning, such as entailment, explicature and implicature (Moeschler 2013b), as well as distributed over different conceptual/procedural drawers.

\section{Conclusion}

This article had the ambition to come back to a very classical analysis of TFCs in natural languages. Doing so, we obtained unexpected results.

First, the formalist view of TFCs does not only explain why conjunction, disjunction and negation are TFCs in natural language but also why a non-confessional connective like the conditional can join the restricted set of TFCs. 
Second, a classical counterexample to a truth-conditional analysis of negation is metalinguistic negation. I assumed in this paper that, even in metalinguistic uses, negation has representational cognitive, truth-conditional effects.

Third, I have given an argument explaining why natural languages have a large set of discourse connectives. I first showed that, first, almost all of them exhibit truth-conditional properties and, second, even if their meaning is nontruth-conditional, it is conceptual and/or procedural and distributed within different layers of meanings, such as entailment, explicatures and implicatures.

Only few explicit proposals have been made in this direction. A new research program, capitalizing on a large set of descriptions of connectives in different languages, should emerge to answer positively to new research questions, such as why some connectives of different languages are at the same time so close and so remote in meaning.

Acknowledgement: This article has been written thanks to the support of the Swiss National Scientific Foundation (project LogPrag n 100012_146093) and the Thematic Network Language \& Communication (project ComplexVar, University of Geneva). Many thanks to Joanna Blochowiak and Cristina Grisot for their help and comments.

\section{References}

Allwood, Jens, Lars-Gunnar Andersson \& Östen Dahl. 1977. Logic in linguistics. Cambridge: Cambridge University Press.

Anscombre, Jean-Claude \& Oswald Ducrot.1977. Deux mais en français? Lingua 43 (1). 23-40. Anscombre, Jean-Clause \& Oswald Ducrot. 1983. L'argumentation dans la langue. Brussels: Mardaga.

Blakemore, Diane. 1987. Semantic constraints on relevance. Oxford: Basil Blackwell.

Blochowiak, Joanna. 2010. Some formal properties of causal and inferential 'because' in different embedding contexts. Generative Grammar in Geneva 6. 191-202.

Blochowiak, Joanna. 2014. A theoretical approach to the quest for understanding: Semantics and pragmatics of whys and becauses. Geneva: University of Geneva PhD dissertation.

Blochowiak, Joanna. 2017. Connectives: Order, causality and beyond. In Joanna Blochowiak, Cristina Grisot, Stephanie Durrleman \& Christopher Laenzlinger (eds.), Formal models in the study of language, 181-197. Cham: Springer.

Blochowiak, Joanna, Thomas Castelain \& Jacques Moeschler. 2015. Les interprétations logiques, temporelles et causales de la conjonction: Une perspective expérimentale. Nouveaux cahiers de linguistique française 32. 71-83.

Carston, Robyn. 2002. Thoughts and utterances: The pragmatics of explicit communication. Oxford: Blackwell. 
Cohen, L. Jonathan. 1971. Some remarks on Grice's view about the logical particles of natural language. In Yoshua Bar-Hillel (ed.), Pragmatics of natural language, 50-68. Dordrecht: Reidel.

de Cornulier, Benoît. 1985. Effets de sens. Paris: Minuit.

Ducrot, Oswald. 1980. Les échelles argumentatives. Paris: Minuit.

Ducrot, Oswald. 1989. Logique, structure, énonciation. Paris: Minuit.

Gazdar, Gerald. 1979. Pragmatics: Implicature, presupposition, and logical form. New York: Academic Press.

Geis, Marc \& Arnold Zwicky. 1971. On invited inferences. Linguistic Inquiry 2 (4). 561-565.

Grice, H. Paul. 1975. Logic and conversation. In Peter Cole \& Jerry L. Morgan (eds.), Syntax and semantics 3: Speech acts, 41-58. New York: Academic Press.

Groupe $\lambda$-l. 1975. Car, parce que, puisque. Revue Romane 10 (2). 248-280.

Horn, Laurence R. 1972. On the semantic properties of logical operators in English. Los Angeles: University of California PhD dissertation.

Horn, Laurence R. 1984. Toward a new taxonomy for pragmatic inference. In Deborah Schiffrin (ed.), Form and use in context: Linguistic applications, 11-42. Washington, DC: Georgetown University Press.

Horn, Laurence R. 1985. Metalinguistic negation and pragmatic ambiguity. Language 61 (1). 121-174.

Horn, Laurence R. 1989. A natural history of negation. Chicago: University of Chicago Press.

Horn, Laurence R. 2004. Implicature. In Laurence R. Horn \& Gregory Ward (eds.), The handbook of pragmatics, 3-28. Oxford: Blackwell.

Humberstone, Lloyd. 2011. The connectives. Cambridge, MA: MIT Press.

Lakoff, Georges. 1971. The role of deduction in grammar. In Charles J. Fillmore \& D. Terence Langendoen (eds.), Studies in linguistic semantics, 62-70. Irvington: Holt, Rinehart \& Winston.

Levinson, Stephen C. 2000. Presumptive meanings: The theory of generalized conversational implicature. Cambridge, MA: MIT Press.

Lewis, David. 1973. Counterfactuals. Oxford: Basil Blackwell.

Lohiniva, Karoliina. 2014. Squares and scales: A study of opposition and entailment. Geneva: University of Geneva MA dissertation.

Lohiniva, Karoliina. 2017. Concessivity implies scalarity and impositive updating. Manuscript. Geneva.

Mauri, Caterina. 2008. Coordination relations in the languages of Europe and beyond. Berlin: De Gruyter.

Mauri, Caterina \& Johan van der Auwera. 2012. Connectives. In Kasia M. Jaszczolt \& Keith Allan (eds.), Cambridge handbook of pragmatics, 377-401. Cambridge: Cambridge University Press.

Mercier, Hugo \& Dan Sperber. 2017. The enigma of reason: A new theory of human understanding. London: Allen Lane.

Moeschler, Jacques. 1989. Modélisation du dialogue: Représentation de l'inférence argumentative. Paris: Hermès.

Moeschler, Jacques. 1997. La négation comme expression procédurale. In Danielle Forget, Paul Hirschbühler, France Martineau \& Maria-Luisa Rivero (eds.), Negation and polarity: Syntax and semantics, 231-249. Amsterdam: John Benjamins.

Moeschler, Jacques. 2010. Negation, scope and the descriptive/metalinguistic distinction. Generative Grammar in Geneva 6. 29-48. 
Moeschler, Jacques. 2011. Causal, inferential and temporal connectives: Why parce que is the only causal connective in French. In Sylvie Hancil (ed.), Marqueurs discursifs et subjectivité, 97-114. Rouen: Presses Universitaires de Rouen et du Havre.

Moeschler, Jacques. 2013a. How 'logical' are logical words? Negation and its descriptive vs. metalinguistic uses. In Maite Taboada \& Radoslava Trnavac (eds.), Nonveridicality and evaluation: Theoretical, computational and corpus approaches, 76-110. Leiden: Brill.

Moeschler, Jacques. 2013b. Is a speaker-based pragmatics possible? Or how can a hearer infer a speaker's commitment? Journal of Pragmatics 43 (1). 84-97.

Moeschler, Jacques. 2016. Where is procedural meaning? Evidence from discourse connectives and tenses. Lingua 175/176. 122-138.

Moeschler, Jacques. 2017a. Formal and natural languages: What does logic tell us about natural language? In Anne Barron, Yueguo Gu \& Gerald Steen (eds.), The Routledge handbook of pragmatics, 241-256. London: Routledge.

Moeschler, Jacques. 2017b. Back to negative particulars: A truth-conditional account. In Stavros Assimakopoulos (ed.), Pragmatics and its interfaces, 7-32. Berlin: De Gruyter.

Moeschler, Jacques. 2017c. How speaker meaning, explicature and implicature work together: Evidence from logical connectives and quantifiers. In Rachel Giora \& Michael Haugh (eds.), Doing pragmatics interculturally: Cognitive, philosophical, and sociopragmatic perspectives, 215-232. Berlin: De Gruyter.

Moeschler, Jacques. forthc. The semantics-pragmatics interface: How it works, why we need it, and where it is? In Pierre Saint-Germier (ed.), Language, evolution and mind: Essays in honor of Anne Reboul, 3-27. London: College Publications.

Moeschler, Jacques \& Anne Reboul. 1994. Dictionnaire encyclopédique de pragmatique. Paris: Seuil.

Moeschler, Jacques \& Anne Reboul. 2001. Conditionnel et assertion conditionnelle. In Patrick Dendale \& Liliane Tasmowski (eds.), Le conditionnel en français, 147-167. Paris: Klinsieck.

Sperber, Dan \& Deirdre Wilson. 1995. Relevance: Communication and cognition. Oxford: Basil Blackwell.

Sweetser, Eve E. 1990. From etymology to pragmatics: Metaphorical and cultural aspects of semantic structure. Cambridge: Cambridge University Press.

van der Auwera, Johan. 1997a. Conditional perfection. In Angeliki Athanasiadou \& René Dirven (eds.), On conditionals again, 169-190. Amsterdam: John Benjamins.

van der Auwera, Johan. 1997b. Pragmatics in the last quarter century: The case of conditional perfection. Journal of Pragmatics 27 (3). 261-274.

von Fintel, Kai \& Lisa Matthewson. 2008. Universals in semantics. The Linguistic Review 25 (1/2). 139-201.

Wilson, Deirdre \& Dan Sperber. 2012. Meaning and relevance. Cambridge: Cambridge University Press.

Zufferey, Sandrine. 2010. Lexical pragmatics and theory of mind: The acquisition of connectives. Amsterdam: John Benjamins.

Zufferey, Sandrine. 2012. 'Car, parce que, puisque' revisited: Three empirical studies on French causal connectives. Journal of Pragmatics 44 (2). 138-153. 